\title{
DIREITO HUMANO À SAÚDE, ACESSO A MEDICAMENTOS E PROPRIEDADE INDUSTRIAL: INTERPRETAÇÃO DO CONCEITO DE INVENÇÃO E DOS REQUISITOS DE PATENTEABILIDADE NO ÂMBITO FARMACÊUTICO
}

\author{
HUMAN RIGHT TO HEALTH, ACCESS TO MEDICINES AND INDUSTRIAL \\ PROPERTY: INTERPRETATION OF THE DEFINITION OF INVENTION AND \\ PATENTABILITY REQUIREMENTS IN THE PHARMACEUTICAL FIELD
}

\section{RESUMO}

${ }^{1}$ Maria Cristina Gomes da Silva d'Ornellas ${ }^{2}$ Pâmela da Costa Noronha

O objetivo do artigo é colaborar com a discussão sobre a possibilidade de harmonização dos critérios de análise dos pedidos de patente para medicamentos. Apresenta reflexões sobre interpretação do conceito de invenção e dos requisitos de patenteabilidade, para observar se tal iniciativa de harmonização contribuiria com o acesso a medicamentos e com a proteção do direito humano à saúde. Esta análise utiliza como método de abordagem o dedutivo e de procedimento o monográfico, baseando-se (a) de doutrina nacional e estrangeira (b) de instrumentos legais internacionais e legislações estrangeiras e (c) leis e decretos nacionais, além de regulamentações adotadas administrativamente.

Palavras-chave: Direito humano à saúde; Acesso a medicamentos; Patentes farmacêuticas; Requisitos de patenteabilidade; TRIPS

\begin{abstract}
The objective this paper is to contribute in the discussion about the possibility of harmonizing the criteria for analysis of patent applications for medicines. It presents reflections about interpretation of invention concept and of the patentability requirements, to observe if such harmonization initiative would contribute to access to medicines and the protection of the human right to health. This analysis uses as a method deductive of approach and the monographic procedure, based on (a) national and foreign doctrine (b) international legal instruments and foreign laws and (c) national laws and decrees, and regulations adopted administratively.
\end{abstract}

Keywords: Human right to health; Medicines acess; Pharmaceutical patentes; Patentability requirements; TRIPS

\footnotetext{
${ }^{1}$ Doutora em Direto pela Universidade Federal do Rio Grande do Sul - UFRGS, Rio Grande do Sul (Brasil). Professora da Graduação e do Mestrado em Direito pelo Centro Universitário Ritter dos Reis - UniRitter, Rio Grande do Sul (Brasil). E-mail: crisdornellas@yahoo.com.br

${ }^{2}$ Mestranda em Direitos Humanos pelo Centro Universitário Ritter dos Reis - UniRitter, Rio Grande do Sul (Brasil). E-mail: pamelacostanoronha@gmail.com
} 


\section{INTRODUÇÃO}

A Constituição da Organização Mundial da Saúde (OMS), aprovada em 22 de julho de 1946, afirmou em seu preâmbulo que "o gozo do mais alto nível possível de saúde é um dos direitos fundamentais de todo ser humano, sem distinção de raça, religião, credo político e situação social e econômica". Desde então, o direito à saúde foi reconhecido no direito internacional dos direitos humanos e incluído em diferentes instrumentos, tratados e declarações internacionais. A Declaração Universal dos Direitos Humanos (DUDH), artigo 25 (1) estabelece que "todo ser humano tem direito a um padrão de vida capaz de assegurar a si e a sua família, saúde e bem estar, inclusive alimentação, vestuário, habitação, cuidados médicos e os serviços sociais indispensáveis (...)”, enquanto no Pacto Internacional sobre Direitos Econômicos, Sociais e Culturais (PIDESC), artigo 12 (1), está expresso que os Estados Parte do Pacto "reconhecem o direito de todas as pessoas de gozar do melhor estado de saúde física e mental possível de atingir”. (ONU, DUDH, 1948; ONU, PIDESC, 1966)

Infelizmente, no entanto, não são poucos os desafios enfrentados na busca de eliminar a distância existente entre compreender o direito à saúde como um direito humano e, efetivamente, tornar esse direito uma realidade. A garantia/implementação de um direito social, tal como o direito humano à saúde implica na produção de bens - medicamentos, equipamentos, etc. - e/ou serviços - prestação de atenção médica.

Diante deste contexto, a ideia de acesso à saúde tem sido objeto de muito interesse. Sanchez e Ciconelli salientam que, atualmente, as principais características de acesso à saúde são resumidas em quatro dimensões: disponibilidade, aceitabilidade, capacidade de pagamento e informação. (SANCHEZ e CICONELLI, 2012, pp. 261-62) Entre estas cinco dimensões, a relativa à capacidade de pagamento, naturalmente, compreende a questão de custos. Despesas com consultas médicas e/ou compra de medicamentos estão entre os aspectos analisados nesta dimensão. Neste sentido, esta também incorpora fatores relacionados à renda ou fonte de renda dos indivíduos e a decisão destes em recorrer ao sistema público de saúde ou arcar com pagamentos relacionados à contratação de seguros privados de saúde.

É evidente que a busca da concretização do direito à saúde toca questões relativas a custos e despesas. De fato, um ponto preocupante a ser referido é que "(o)s gastos com a saúde estão crescendo em ritmo acelerado devido, sobretudo, à incorporação de novas tecnologias, nas quais se inclui a fabricação de medicamentos" e no âmbito do acesso a medicamentos a 
capacidade aquisitiva, possivelmente, é a “mais afetada negativamente pela proteção patentária de produtos e processos farmacêuticos". (SCHEFFER e VIEIRA, 2015, p.251)

Não obstante outros elementos, então, não há como afastar o fato de que a atual estrutura normativa internacional de proteção da propriedade intelectual está entre os fatores que mais contribuem para dificultar o acesso e a disponibilidade de um sistema de proteção e de cuidados à saúde, sobretudo, para as populações de países em desenvolvimento.

O regime jurídico brasileiro para a atual proteção da propriedade intelectual foi baseado no Acordo sobre Aspectos dos Direitos de Propriedade Intelectual Relacionados ao Comércio (TRIPS). O TRIPS foi adotado no âmbito da Organização Mundial do Comércio (OMC) e teve como objetivo estabelecer os padrões normativos mínimos de proteção para as criações intelectuais para países membros da referida organização. Os direitos de propriedade intelectual buscam garantir a apropriação e a exploração de bens intangíveis e/ou incorpóreos que, necessariamente, decorrem da capacidade inventiva e/ou criadora do intelecto humano. Os direitos relativos à propriedade intelectual são protegidos em uma área que se divide em duas principais ramificações: direitos autorias e direitos de propriedade industrial. Os direitos autorais lidam, sobretudo, com a proteção de softwares e de criações do espírito relativas às obras artísticas, culturais e científicas, enquanto os direitos de propriedade industrial abrangem a proteção de patentes, desenhos industriais e marcas. A patente, neste caso, é o direito de exploração exclusiva concedida pelo Estado ao titular de uma invenção. No caso do Brasil, o reconhecimento de patentes para produtos e processos farmacêuticos somente veio com a promulgação da Lei 9.279, de 14 de maio de 1996 (Lei 9.279/96), diante dos compromissos assumidos internacionalmente pelo país no âmbito do acordo TRIPS/OMC.

É fato que os direitos conferidos ao titular por meio do patenteamento na área farmacêutica interferem tanto em questões associadas ao acesso a medicamentos quanto na elaboração de políticas públicas de saúde. Porém, isso não significa afirmar que a proteção patentária concedida às invenções do setor - per se - está relacionada a todos os desafios enfrentados para preservação do direito humano à saúde. Estes desafios também podem estar na forma em que os dispositivos do acordo TRIPS foram acolhidos pelas legislações nacionais e, posteriormente, interpretados e implementados pelas autoridades competentes. Ou seja, o problema pode estar na falta de critérios uniformes para a interpretação do conceito de invenção e para a análise dos requisitos de patenteabilidade para o setor farmacêutico.

Assim, o objetivo deste artigo é colaborar com a discussão sobre a possibilidade de harmonização dos critérios observados na análise dos pedidos de patente para medicamentos. 
Este traz, então, reflexões relativas à interpretação do conceito de invenção e dos requisitos de patenteabilidade, a fim de observar se tal iniciativa poderia contribuir com o acesso da população a medicamentos e, por conseguinte, com a proteção do direito humano à saúde. Para tanto, utiliza como método de abordagem o dedutivo e de procedimento, o método monográfico. Dentre as técnicas utilizadas, destaca-se a análise (a) de doutrina nacional e estrangeira (b) de instrumentos legais internacionais e legislações estrangeiras e (c) legislação e projetos de leis nacionais, além de regulamentações elaboradas administrativamente pelos órgãos competentes.

\section{A proteção patentária para o setor farmacêutico na perspectiva do Acordo TRIPS}

A adoção do Acordo sobre Aspectos dos Direitos de Propriedade Intelectual Relacionados ao Comércio (TRIPS), em 1995, foi um passo chave no âmbito da ordem jurídica internacional. Este abrange a principal estrutura normativa internacional voltada para o controle dos direitos de propriedade intelectual. Antes da adoção do acordo TRIPS, eram outros tratados internacionais firmados no âmbito da Organização Mundial da Propriedade Intelectual (OMPI), tais como a Convenção União de Paris para a proteção da propriedade industrial (CUP) e Convenção da União de Berna para a proteção das obras literárias e artísticas, os quais contemplavam os direitos de propriedade conferidos às criações intelectuais.

Uma das mudanças mais importantes introduzidas através do acordo TRIPS foi o previsto em seu artigo 27(1), que passou a exigir dos membros da OMC a proteção patentária para produtos e processos desenvolvidos em todos os campos tecnológicos, desde que atingidos os requisitos legais: novidade, atividade inventiva e aplicação industrial. Além de patentes para produtos e processos na área farmacêutica, esse dispositivo introduzido pelo acordo possibilitou aos países que assim desejassem a concessão de patentes de uso para medicamentos. É importante salientar que antes do acordo TRIPS muitos países não reconheciam patenteamento de medicamentos. No caso do Brasil, por exemplo, até o vigor da Lei n. ${ }^{\circ}$ 9.279/1996 os produtos farmacêuticos de qualquer tipo, modificações ou processos desenvolvidos para a sua obtenção, não eram passíveis de proteção patentária.

No entanto, o artigo $8^{\circ}$ do acordo TRIPS prevê a possibilidade para os membros da OMC de adotarem outras "medidas necessárias para proteger a saúde pública e nutrição e para promover o interesse público em setores de importância vital para o seu desenvolvimento 
socioeconômico e tecnológico". Naturalmente, a interpretação do previsto no artigo 8o do acordo pode implicar na limitação de alguns direitos patentários e, assim, contribuir para a

Garantia do acesso a medicamentos. Da mesma forma, o acordo TRIPS também possibilita que sejam excluídos da proteção patentária os métodos diagnósticos, terapêuticos e cirúrgicos de tratamento de seres humanos e animais e invenções que atentam contra a ordem pública e fundamentos morais da sociedade.

A licença compulsória estabelecida em seu artigo 31 é uma dessas medidas e/ou flexibilidades. As razões pelas quais os membros da OMC decidem conceder uma licença compulsória não foram limitadas pelo acordo TRIPS. (HESTERMEYER, 2007, p.229) O Acordo menciona algumas, tais como em situações de emergências nacionais ou outras de extrema urgência; uso público não-comercial e condutas anticompetitivas. Porém, o licenciamento compulsório é um recurso que poderá ser utilizado diante de circunstâncias que vão além dessas que foram explicitamente mencionadas. O detalhamento no artigo 31 do TRIPS das condições exigidas para a concessão do licenciamento compulsório pelos membros da OMC foi, provavelmente, o ponto que impôs grandes desafios para os países sem capacidade industrial no setor farmacêutico. A Declaração de Doha sobre o Acordo TRIPS e Saúde Pública confirmou o direito dos membros da OMC de utilizarem as flexibilidades do TRIPS, além de ter assegurado que estes têm a liberdade para determinar quais as situações que configuram "emergência nacional" ou outra circunstância de "extrema urgência" - (“[...] ficando entendido que crises de saúde pública, incluindo as relacionadas a HIV/AIDS, tuberculose, malária e outras epidemias, podem representar emergência nacional ou outras circunstâncias de extrema urgência"). Posteriormente, adveio a "Implementação do $6^{\circ}$ paragrafo da Declaração de Doha sobre o acordo TRIPS e Saúde Pública”, em 30 de agosto de 2003, implementada em 2005. A decisão determinou como os países que não possuem capacidade de produzir medicamentos poderiam fazer uso da licença compulsória. Assim, esta tratou de permitir a exportação de medicamentos genéricos, através de licenças compulsórias, para países sem capacidade própria de produção.

É claro que apesar das deliberações da Declaração de Doha e/ou das modificações já inseridas no Acordo TRIPS, ainda permanecem desafios que dificultam o alcance do direito humano à saúde relativo ao acesso a medicamentos. Entretanto, é importante compreender que tais desafios podem não estar - tão somente - na obrigatoriedade prevista pelo TRIPS de proteção da propriedade intelectual estendida para todos os setores tecnológicos ou nas limitações impostas para o licenciamento compulsório. 
$\mathrm{Na}$ verdade, estes podem estar nas próprias leis relativas à análise e concessão dos pedidos de patente depositados junto aos órgãos registrários, visto que o TRIPS garante aos Estados membros da OMC a possibilidade de escolha na forma de implementação em âmbito interno/nacional, do estabelecido em seus dispositivos legais.

\section{Implementação da legislação patentária para o setor farmacêutico}

Tal como já foi referido anteriormente, a proteção da propriedade industrial é disciplinada pela Lei 9.279/1996 e, assim, abrange os direitos relativos à concessão de patentes para invenções e modelos de utilidade. A proteção patentária na legislação brasileira é, então, classificada a partir de dois critérios: o primeiro diz respeito ao fim que se dedicam, enquanto o segundo ao objeto que protegem. Quanto ao primeiro critério, a patente pode ser de invenção ou de modelo de utilidade. As invenções patenteáveis são aquelas que representam ideias que encontram na prática uma solução para um problema técnico específico. A proteção para os modelos de utilidade, no entanto, existe quando o objeto a ser patenteado apresenta uma nova forma ou disposição que resulte em melhoria funcional no seu uso ou fabricação. Em relação ao segundo critério, uma patente de invenção pode ser de um produto ou processo. As patentes de produto protegem coisas e. as de processo, a maneira de fazer ou usar algo.

Normalmente, o privilégio do patenteamento se justifica quando a recompensa financeira recebida pelo seu criador ou titular incentiva as inovações e eleva o nível tecnológico das indústrias do setor envolvido, através da reposição dos valores investidos em pesquisa e desenvolvimento. Machnicka explica que a razão para a adoção de um rígido sistema patentário está, sobretudo, baseado em três pontos: 1. estabelecer uma forma capaz de incentivar os inventores a divulgarem as suas invenções, visto que isto ampliaria o âmbito de conhecimentos tornados públicos; 2. estimular o desenvolvimento de novas tecnologias e 3. encorajar os investimentos em novos produtos e processos. (2012, p.406). No que tange aos produtos e processos farmacêuticos, porém, há oposição à proteção patentária porque esses bens são de interesse da saúde pública e essenciais para o bem-estar das populações. (CASSIER, 2004)

Conforme o previsto no acordo TRIPS, os países são autônomos para definirem as suas próprias leis relativas à análise e concessão dos pedidos de patente depositados, assim como para delinear o exigido para estabelecer o cumprimento ou não dos requisitos de patenteabilidade. Tanto o conceito quanto a forma de aplicação de cada um desses critérios 
pode variar, dependendo da legislação, autoridade examinadora e/ou corte em que a proteção patentária é submetida e/ou posta em análise. (CORREA, 2016, p. 2) Entretanto, em termos gerais, a concessão de uma patente está condicionada ao atendimento dos requisitos da novidade, atividade inventiva e aplicação industrial.

O primeiro dos requisitos - novidade - está relacionado ao desenvolvimento (no âmbito intelectual) que deverá ser proporcionado pela nova tecnologia, produto ou processo que está sob análise. Este produto ou processo deve alcançar algum incremento na capacidade produtiva até então disponível à sociedade, na medida em que deve representar um passo além no setor tecnológico ou industrial ao que se destina (BARBOSA, 1999, p. 58). A legislação brasileira estabelece que novo é tudo aquilo que ainda não pertence ao estado da técnica. Nesse sentido, a regra geral determina que o objeto da patente - produto ou processo - não deve ter sido revelado em lugar algum, seja por via escrita, oral ou pelo seu uso, antes de efetivado o seu depósito no órgão competente - Instituto Nacional da Propriedade Industrial (INPI). (BRASIL, 1996, art. 11) Para os casos em que tal revelação tenha ocorrido sem o referido depósito, a legislação prevê a possibilidade do resguardo deste direito de proteção, quando esta se enquadrar na situação denominada como período de graça. Isto significa afirmar, que tal divulgação não pode ter ocorrido em um período que exceda aos 12 meses que precederam a data do depósito do invento no Brasil. (BRASIL, 1996, art. 12)

Muitos países não concedem o período de graça. Nas Comunidades Europeias, por exemplo, a inobservância do requisito do prazo quanto ao depósito e posterior divulgação do invento ou do modelo de utilidade importa em perda da novidade. Nem todo sistema jurídico assegura em sua legislação nacional a prerrogativa do período de graça porque, afinal, o próprio acordo TRIPS garante que os Estados membros da OMC escolham a forma que desejam implementar o previsto em seus dispositivos. Assim, ao adotarem suas políticas nacionais, os Estados determinam o alcance das divulgações já ocorridas e definem o que se encontra no "estado da técnica".

Entretanto, em que pese existirem posicionamentos diferentes sobre a questão, se faz necessário alertar que nem toda divulgação ocorrida no prazo anteriormente referido será, necessariamente, abrangida no conceito de período de graça. BARBOSA, por exemplo, atrela as suas reflexões sobre o período de graça às assimetrias existentes quanto ao assessoramento e/ou conhecimentos relativos aos direitos de propriedade intelectual, entre inventores individuas, pesquisadores, pequenas e médias empresas, por um lado, e grandes empresas por outro. Assim, segundo o expresso pelo autor: 
(...) o período de graça é objetivo, e sua proteção não é afetada pelo descuido ou falta aparente ou real de intento em proteger o valor econômico do invento. Porém, não obstante o intuito protecionista do instituto, voltado ao inventor individual ou pequena empresa que historicamente - tentem a perder o direito de pedir patente por divulgarem o invento antes do depósito, o que se tem neste dispositivo é uma suspensão do período em que a tecnologia cai em domínio público. Assim, a interpretação de seu teor levará em conta a exigência constitucional de balanceamento entre interesses contrastantes, sem perder de vista à proteção ao mais fraco, que pode ser o inventor, mas também sem frustrar os interesses da comunidade, que é de ter tecnologia de uso livre, ou logo publicada para conhecimento público. Assim, nenhuma contemplação poderá haver no caso de invento de titularidade uma grande ou média empresa que descura de pretender proteção a seus inventos; dormientibus non soccurit jus. Para estes, há que se aplicar o período de graça com o máximo de restrição. (BARBOSA, 2002)

Ainda nesse contexto, é importante analisar que se a proteção patentária busca recompensar a capacidade inventiva, encorajar os progressos de ordem técnica e incentivar a disseminação de inovações, o patenteamento somente se justifica quando o requisito da atividade inventiva está presente em um novo produto ou processo. Diante do previsto na legislação brasileira, a invenção e o modelo de utilidade são dotados de atividade inventiva e ato inventivo quando não-óbvios à luz do que já é conhecido, ou ainda, apresentem uma nova funcionalidade que não decorra de maneira comum ou vulgar do estado da técnica. O requisito da atividade inventiva se refere, então, ao empenho intelectual do inventor para a obtenção do resultado objeto de proteção. Um avanço trivial sobre a tecnologia anterior não mereceria o direito de proteção. O ato inventivo, por sua vez, é um atributo que deve estar presente nos modelos de utilidade. Neste caso, diz respeito à nova forma ou disposição presente em um objeto que depois dessa alteração conte com uma melhoria funcional no seu uso ou na sua fabricação (independentemente da mudança ter decorrido de combinações óbvias ou simples combinações de características do estado da técnica).

Correa salienta que o cumprimento desse requisito é particularmente importante no setor farmacêutico, porque o patenteamento poderia ser utilizado através de estratégias usadas para impedir a entrada no mercado de medicamentos genéricos com preços mais baixos. (2016, p.4) Moreira refere que o desenvolvimento de produtos novos ou aperfeiçoados é, tipicamente, classificado em dois tipos de inovação: inovação radical e inovação incremental. O autor afirma, ainda, que tanto as definições quanto os limites de cada uma das inovações são controversos e incertos, mas, de uma forma geral, há o consenso de que inovações radicais 
compreendem tecnologias inéditas ou revolucionárias e inovações incrementais compreendem aperfeiçoamentos ou melhoramentos em tecnologias existentes e estabelecidas. (MOREIRA, 2010) No âmbito do patenteamento no setor farmacêutico e do acesso a medicamentos, Guimarães e Corrêa apresentam dados alarmantes. Estes autores, baseados em um estudo realizado nos Estados Unidos pelo National Institute for Health Care Management (NIHCM FOUNDATION, 2002 apud GUIMARÃES e CORRÊA, 2012, p. 5) afirmam que a partir da década de 1990 o número de patentes para proteger invenções incrementais aumentou consideravelmente, sobretudo, após o advento do acordo TRIPS. Entre o ano de 1989 e 2000, somente " $15 \%$ de todos os medicamentos aprovados nos Estados Unidos ofereciam significativas inovações clínicas.” Na esfera europeia, os autores também trataram de alertar para o fato de que a indústria farmacêutica pode utilizar estratégias no campo da propriedade industrial para postergar a disponibilidade de medicamentos genéricos no mercado. Nesse sentido, referem o caso de um único medicamento ter logrado alcançar cerca de 1.300 patentes válidas na Europa. (GUIMARÃES e CORRÊA, 2012, p. 5)

Portanto, é possível afirmar que se comparado com os demais requisitos de patenteabilidade, esse parece ser o que apresenta maior margem para a inserção de critérios subjetivos na análise feita pelo examinador do produto ou processo que busca a proteção. No caso do Brasil, o dispositivo legal não exige que esta análise seja feita por mais de um técnico no assunto. Há invenções, no entanto, com alto grau de complexidade, cuja análise merece contar com a contribuição ou expertise de técnicos com conhecimentos de diversas áreas. A definição de quem é o técnico no assunto capaz de avaliar a presença de inventividade em um novo produto ou processo utiliza, normalmente, como parâmetro a observação se este é um "profissional graduado na especialidade, detentor dos conhecimentos acadêmicos comuns, e da experiência média de um engenheiro ou técnico, operando no setor industrial pertinente". (BARBOSA, 2002a, p.79)

Também deve ser referido que a avaliação sobre a presença ou não de atividade ou ato inventivo em uma determinada invenção ou modelo de utilidade é feita a partir dos conhecimentos existentes à época em que o novo produto ou processo foi desenvolvido. Barbosa observa que esta análise ou avaliação deve ser "prospectiva a partir do documento mais próximo, e não retrospectiva, a partir da nova invenção". Na verdade, há a tendência de tudo parecer óbvio se comparado com uma nova solução já existente. (BARBOSA, 2002a, p.70) Assim, há situações em que o reconhecimento da não-obviedade - pelos examinadores e, em algumas situações pelos tribunais - advém da observância de fatores secundários, que incluem: 
(a) se a invenção soluciona um problema existente há muito tempo; (b) se esta supera falhas anteriormente identificadas; e/ou (c) se esta conta com o sucesso comercial. São fatores observados e que auxiliam a descartar a obviedade porque esclarecem que uma invenção aparentemente óbvia era, na verdade, um problema técnico que há muito tempo outras pessoas vinham falhando em suas tentativas para solucioná-lo. (OMPI, 2005, p.25)

Por fim, a legislação exige que a invenção ou modelo de utilidade tenha aplicação industrial. Barbosa esclarece que o requisito da aplicação industrial é o que diz respeito à utilidade econômica do produto ou processo objeto da análise da proteção patentária. (1999, p. 60) Nesse sentido, para que uma patente seja obtida é necessário que o inventor demonstre algum tipo de proveito para a sociedade.

Diante de toda esta análise feita sobre os requisitos de patenteabilidade permitidos pelo acordo TRIPS e implementados pelos Estados membros da OMC, é indispensável apontar que, atualmente, o Brasil conta com um sistema de patentes peculiar/controverso para produtos e processos farmacêuticos, pois para este setor divide o exame de patenteabilidade entre dois órgãos administrativos - Instituto Nacional de Propriedade Intelectual (INPI) - subordinado ao Ministério do Desenvolvimento, Indústria e Comércio exterior - e Agência Nacional de Vigilância Sanitária (ANVISA) - vinculada ao Ministério da Saúde. Para os produtos farmacêuticos, então, a concessão de patentes também é regida pelo disposto no artigo $229 \mathrm{C}$ da Lei 9.279/1996, acrescido pela Lei 10.196/2001, que incluiu passos adicionais no processo de exame de patentes sobre produtos farmacêuticos - se comparado com o procedimento seguido para os demais setores. Pelo texto da Lei, a "a concessão de patentes para produtos e processos farmacêuticos está sujeita à autorização prévia da Agência Nacional de Vigilância Sanitária". Entretanto, a referida lei não esclareceu se havia sido conferido à ANVISA a autoridade necessária para avaliar os requisitos de patenteabilidade. Até o ano de 2001, todos os pedidos de patente depositados no Brasil eram somente analisados pelo INPI. A partir da inserção da figura jurídica da anuência prévia para as patentes de produtos e processos farmacêuticos, todas as análises dos pedidos encaminhados pelo setor passaram a depender de decisões proferidas no âmbito da ANVISA. A discordância entre estas duas autoridades se tornou tão evidente que acabou gerando uma mudança no procedimento seguido para a análise dos pedidos de patente de medicamentos. O que era previamente avaliado pelo INPI passou somente a ser analisado por esta autoridade depois de deferido pela ANVISA.

O INPI nunca esteve convencido sobre a capacidade da ANVISA para realizar esta análise. No entanto, a Agência elaborou a Resolução RDC 21/2013 e atualizou o processamento 
de pedidos de patentes. Desta forma estabeleceu que a ANVISA examinará os pedidos de patentes encaminhados pelo INPI, à luz da saúde pública. Nesse sentido, a Resolução determinou que o papel desempenhado pela ANVISA vai além da verificação se o produto ou processo farmacêutico contido no pedido de patente apresenta risco à saúde, mas também inclui a análise dos requisitos de patenteabilidade. (ANVISA, 2013, art. 4)

Muito das divergências existentes entre o INPI e a ANVISA envolve, por exemplo, a possibilidade de concessão de patente para novas formas polimórficas de uma molécula já conhecida. O polimorfismo é identificado quando uma mesma molécula é capaz de cristalizar em duas ou mais formas. (JANNUZZI, VASCONCELLOS E SOUZA, 2008, p. 1211) Um grande número de depósitos de pedidos de patente de polimorfos estão sendo feitos e muitos estão sendo concedidos. No entanto, Correa esclarece que isto seria o patenteamento de uma mesma substância ativa em uma nova forma cristalina. Ademais, "o poliformismo é uma propriedade natural resultante das condições específicas sob as quais um composto é obtido", qualquer composto químico que apresente esta capacidade irá "naturalmente cristalizar-se em sua forma mais estável, mesmo sem qualquer tipo de intervenção humana". (GUIMARÃES e CORRÊA, 2012, p. 9) Por esta razão, os escritórios de patente e tribunais estariam se tornando cada vez mais relutantes a continuidade de tais práticas. (CORREA, 2016, p.15) Como Barbosa afirma, a "mera descoberta de formas polimórficas de um mesmo produto perdeu o atributo de inventividade, essencial para a concessão de uma patente". (BARBOSA, sem data, p.2)

Outro exemplo em que há a possibilidade das indústrias farmacêuticas buscarem a extensão da proteção patentária para medicamentos cuja patente original já expirou ou está por expirar é conhecido como patente de segundo uso médico. Neste tipo de patenteamento o que se visa proteger é um novo uso terapêutico para um princípio ativo já conhecido. Nas palavras de Correa, patentes de segundo uso médico não podem ser concedidas porque não são invenções. $\mathrm{O}$ reconhecimento de um novo uso terapêutico de um medicamento já conhecido ocorre em decorrência tanto da realização de testes clínicos quanto da observação dos seus efeitos durante o período em que foi comercializado. (CORREA, 2016, p. 26) Desta forma, se está diante da descoberta de uma propriedade intrínseca de um componente já patenteado.

Questões acerca do escopo das patentes de segundo uso já foram levantadas no âmbito do Escritório Patentário Europeu, visto que este concedeu patentes “direcionadas para o uso de uma substância conhecida ou composição na fabricação de um medicamento para uma aplicação terapêutica nova e original.” (ROOX et al., 2008) Um exemplo desta prática estaria na patente concedida para dosagens diferentes de um mesmo medicamento no tratamento de 
hiperplasia benigna de próstata e no tratamento de calvície masculina. (ROOX et al., 2008) Isto porque, a patenteabilidade de medicamentos cujo princípio ativo é conhecido, mas apresenta um novo uso terapêutico não é exigida pelo TRIPS e, assim, admitida em alguns de seus Estados membros.

Recentemente, o INPI editou a Resolução n. 169, de 15 de julho de 2016, que institui as Diretrizes de Exame de Pedidos de Patente - Bloco II - Patenteabilidade. Neste documento, que até onde consta também deverá ser considerado pelos examinadores da ANVISA, determinou, por exemplo, que na "determinação da atividade inventiva de uma invenção de novo uso de um produto conhecido, usualmente os seguintes fatores precisam ser considerados: a proximidade o campo técnico do novo uso com o do uso anterior e o efeito técnico inesperado do novo uso". No entanto, esta nova resolução acabou de ser estabelecida e, por isso, ainda não se conhece as reações que irá gerar.

Assim, cabe reiterar que a diversidade de interpretações para o conceito de invenção diante dos mesmos requisitos de patenteabilidade e, por conseguinte, a maneira como os pedidos de patentes farmacêuticas são analisados pode ter implicações importantes para a saúde pública. Na verdade, a concessão de patentes para produtos ou processos farmacêuticos de méritos duvidosos, ainda hoje, está entre os principais problemas que obstam o direito humano de acesso à saúde.

\section{CONCLUSÃO}

Em linhas gerais, a proteção da propriedade industrial tem entre as suas atribuições garantir o amparo legal e a motivação necessária para manter o desenvolvimento de criações que são fruto do intelecto humano. Inserido neste contexto também está o setor da saúde - que inclui o desenvolvimento de medicamentos.

Embora o licenciamento compulsório esteja entre as ferramentas disponíveis aos membros da OMC para atender questões relacionadas ao acesso a medicamentos, este somente ocorre depois que se esgotam as possibilidades de negociações entre o país e a empresa farmacêutica envolvida, além de exigir o pagamento dos royalties apropriados para o titular da patente. Assim, mesmo imaginando a possibilidade da busca do licenciamento compulsório nas situações em que o direito humano à saúde fosse ameaçado, não faria sentido ter que recorrer a tal alternativa para minimizar os efeitos negativos de uma patente farmacêutica mal concedida. 
A opção pelo não patenteamento em casos em que o que se busca proteger são, por exemplo, formas polimórficas ou segundos usos médicos que não atendem aos requisitos de patenteabilidade, evitaria uma série de preocupações pois, esta atitude teria como objetivo evitar abusos sem, no entanto, caracterizar uma interferência do direito do titular de uma patente.

Nesse sentido, o TRIPS teve o objetivo de regular e/ou limitar os instrumentos nacionais relativos à proteção da propriedade industrial para os membros da $\mathrm{OMC}$, por um lado, mas ainda deixou alguma discricionariedade para estes países legislarem sobre o tema, por outro. Sobre este último ponto é relevante perceber que no caso da harmonização dos critérios de análise de patenteabilidade, o relativo cerceamento de discricionariedade dos membros da OMC poderia auxiliar no acesso a medicamentos essências a populações carentes, sem no entanto, envolver a adoção de medidas especialmente questionáveis. $\mathrm{Na}$ verdade, a harmonização dos critérios ocorreria a partir de aspectos técnicos e não, envoltos em excessiva subjetividade. Tomando como exemplo o exposto sobre o descompasso existente entre os entendimentos das autoridades brasileiras, INPI e ANVISA, não há como deixar de referir que tal situação poderia não existir.

\section{REFERÊNCIAS}

ANVISA. Resolução-RDC $\mathbf{N}^{\mathbf{2}} \mathbf{2 1}$, de 10 de abril de 2013. Altera a Resolução - RDC $\mathrm{n}^{\circ}$ 45 , de 23 de junho de 2008, que dispõe sobre o procedimento administrativo relativo à prévia anuência da Anvisa para a concessão de patentes para produtos e processos farmacêuticos. Disponível em:

http://bvsms.saude.gov.br/bvs/saudelegis/anvisa/2013/rdc0021_10_04_2013.html. Acesso em: 26 set. 2016.

BARBOSA, Denis Borges. Atividade inventiva: objetividade do exame. 2002a. Disponível em: http://www.denisbarbosa.addr.com/atividade.pdf. Acesso em: 26 set. 2016.

BARBOSA, Denis Borges, Os requisitos da patente de invenção. 2002. Disponível em: http:www.denisbarbosa.addr.com/119.rtf. Acesso em: 26 set. 2016.

BARBOSA, Denis Borges. Polimorfos, Enantiômetros \& coetera - Uma proposta de mudança legislativa. Sem data. Disponível em:

http://www.denisbarbosa.addr.com/arquivos/novidades/polimorfismo.pdf. Acesso em: 26 set. 2016.

BARBOSA, Pedro Marcos Nunes. As patentes farmacêuticas e os Direitos Humanos. Cadernos da Escola de Direito e Relações Internacionais, vol. 11, 2015. 
BRASIL. Lei n. 9.279, de 14 de maio de 1996. Presidência da República, Brasília, 1996. Disponível em: http://www.planalto.gov.br/ccivil_03/Leis/L9279.htm. Acesso em: 26 set. 2016.

BRASIL. Lei n. 10.196, de 14 de fevereiro de 2014. . Presidência da República, Brasília, 2011. Disponível em: http://www.planalto.gov.br/ccivil_03/leis/LEIS_2001/L10196.htm Acesso em: 26 set. 2016.

CASSIER, M. Brevets pharmaceutiques et santé publique en France : opposition et dispositifs spécifiques d'appropriation des médicaments entre 1791 et 2004. Entreprises et Histoire, n. 36, p. 29 - 47, 2004.

CASSIER, M.; CORRÊA, M. Scaling up and reverse engineering: Acquisition of industrial knowledge by copying drugs in Brazil In: CORIAT, B. (Coord.) The Political Economy of HIV/AIDS in Developing Countries. The impacts of TRIPS on Public Health in the South. London: E. Elgar, p. 130-149. 2008.

CERQUEIRA, João da Gama. Tratado da Propriedade Industrial, v. I, 2. Ed. São Paulo: Revista dos Tribunais, 1982.

CORREA, Carlos. Implementing pro-competitive criteria for the examination of pharmaceutical patentes. South Centre Research working paper, n. 64, 2016.

CORREA, Carlos. Integrating Public Health Concerns into Patent Legislation in Developing Countries. South Centre Working Paper, 2000. Disponível em: http://apps.who.int/medicinedocs/pdf/h2963e/h2963e.pdf. Acesso em: 26 set. 2016.

CORREA, Carlos. Patent Examination And Legal Fictions: How Rights are created cn fee of clay. South Centre Research working paper, n. 58, 2014.

DANNEMANN, Siemsen, Bigler \& Ipanema Moreira. Comentários a lei de propriedade industrial e correlatos. Rio de Janeiro: Renovar, 2001.

DI BLASI, Gabriel. A Propriedade Industrial: os sistemas de marcas, patentes e desenhos industriais analisados a partir da Lei n 9.279, de 14 de aio de 1996. Rio de Janeiro: Forense, 2005.

GADELHA, C. A. G. O complexo industrial da saúde e a necessidade de um enfoque dinâmico na economia da saúde. Ciência Saúde Coletiva, São Paulo, v. 8, n. 2, 2003.

GUIMARÃES, Eduardo; CORRÊA, Marilena. Propriedade intelectual e saúde pública: o papel da Agência Nacional de Vigilância Sanitária no patenteamento farmacêutico no Brasil. Revista Eletrônica de Comunicação Informação \& Inovação em Saúde, v. 6, n. 3, 2012. Disponível em: http://www.reciis.icict.fiocruz.br/index.php/reciis/article/view/497. Acesso em: 26 set. 2016. 
HESTERMEYER, Holger. Human rights and the WTO: the case os patents and acess to medicines, Oxford: Oxford University Press, 2007. INPI. Instituto Nacional de Propriedade Intelectual. Resolução 169/201: Instituir as Diretrizes de Exame de Pedido de Patente, 2016. Disponível em: http://www.inpi.gov.br/menu-servicos/patente/legislacaopatente-1. Acesso em: 26 set. 2016.

JANNUZZI, Anna Haydée L.; VASCONCELLOS, Alexandre Guimarães; SOUZA, Cristina Gomes de. Especificidades do patenteamento no setor farmacêutico: modalidades e aspectos da proteção intelectual. Caderno de Saúde Pública, v. 24, n. 6, 2008.

MACHNICKA, Agnieska A. Environmental Protection and Patent Law. In: SANCIN, Vasilka (Ed.), International Environmental Law: Contemporary Concerns and Challenges, Ljubljana: GV Publishing, 2012, p. 405-419.

MOREIRA, Pedro. Patenteabilidade de Inovações Farmacêuticas Incrementais no Brasil: Aceitá-las ou Proibi-las?. Revista da Associação Brasileira da Propriedade Intelectual, n. $108,2010$.

ONU. Declaração Universal dos Direitos Humanos. Disponível em: http://portal.mj.gov.br/sedh/ct/legis_intern/ddh_bib_inter_universal.htm. Acessado em: 25 set. 2016.

ONU. Pacto Internacional sobre Direitos Econômicos, Sociais e Culturais. Disponível em: http://www.planalto.gov.br/ccivil_03/decreto/1990-1994/d0591.htm. Acessado em: 25 set. 2016.

ROOX, Kristof (Ed.). Barreiras relacionadas à patente para entrada de medicamentos genéricos no mercado da União Europeia: uma revisão das fraquezas no atual sistema de patente Europeu e seu impacto no acesso a medicamentos genéricos no mercado. Associação Europeia de Medicamentos Genéricos, 2008. Disponível em: http://www.progenericos.org.br/ProGenerico_Livro.pdf. Acesso em: 26 set. 2016.

SELL, Susan K. What Role for Humanitarian Intellectual Property? The Globalization of Intellectual Property Rights. Minnesota Journal of Law, Science and Technology, v. 6, n. 1, 2004-2005, p. 191-211.

SEYMORE, Sean B. Patent Asymmetries. University of California Davis Law Review. v. 49, 2015-2016.

SCHEFFER, Mario; VIEIRA, Marcela Fogaça. Sistema de pacientes: barreiras para a inovação e o acesso a medicamentos. In: COSTA, Laís; BAHIA, Ligia; GADELHA, Antonio Grabois (Orgs.). Saúde, desenvolvimento e inovação. Rio de Janeiro: Cepesc, IMS/UFRJ, ENSP/FIOCRUZ, IESC/UFRJ, 2015, 2 v, p. 233-268.

SHEMDOE. Georges S. Introduction te intelectual property rights for investigators in health research and institutional intelectual property policy. Acta Tropica. 112S, 2009. 
WTO. World Trade Organization. Agreement on trade-related aspects of intellectual property rights - TRIPS : multilateral trade negotiations the Uruguay round. Genebra, 1994. Disponível em: http://www.inpi.gov.br/legislacao-1/27-trips-portugues1.pdf. Acesso em: 26 set. 2016.

WTO, 2015. World Trade Organization. The separate Doha Declaration explained. Disponível em: https://www.wto.org/english/tratop_e/trips_e/healthdeclexpln_e.htm. Acesso em: 26 set. 2016. 